\title{
Microwave Components Realized by Additive Manufacturing Techniques
}

\author{
Cristiano TOMASSONI ${ }^{1}$, Maurizio BOZZI ${ }^{2}$ \\ ${ }^{1}$ Department of Engineering, University of Perugia, Perugia, Italy \\ ${ }^{2}$ Department of Electrical, Computer and Biomedical Engineering, University of Pavia, Pavia, Italy \\ cristiano.tomassoni@unipg.it, maurizio.bozzi@unipv.it
}

Submitted November 24, 2019 / Accepted December 20, 2019

\begin{abstract}
This paper presents an overview of the use of additive manufacturing (AM) technologies for the implementation of microwave components. Two major technological solutions, based on the AM of plastic materials, are discussed: in the former case, the AM plastic is used as a dielectric material that constitutes the component. Conversely, in the latter case, the plastic material is a mere support of the metallization, thus avoiding the contact of the AM plastic with the electromagnetic field and reducing losses. Several examples are illustrated and discussed, to highlight benefits and limitations of AM techniques in the current scenario of microwave applications.
\end{abstract}

\section{Keywords}

Additive manufacturing (AM), filter, sensor, substrate integrated waveguide (SIW), waveguide

\section{Introduction}

The use of additive manufacturing (AM) techniques, also known as 3D printing, is becoming very popular in a wide range of disciplines, ranging from medicine to mechanics and building construction. In the last few years, AM was also applied in the implementation of microwave components and antennas [1]-[15].

In microwave applications, AM offers unprecedented design flexibility, allowing to implement fully three-dimensional structures, and additional degrees of freedom in the use of dielectric materials, as in some cases it permits to modify the value of dielectric permittivity to the desired value. Moreover, AM guarantees an extremely rapid prototyping and reasonable costs for the manufacturing of small amounts of samples.

Among the various AM technologies available on the market, few of them appear to be particularly convenient for microwave applications, because they combine the needed accuracy and the design flexibility with low costs for facilities and fabrication process.
In this paper, the AM of plastic materials is mainly considered. Two major technological solutions are discussed: one is based on the use of the AM plastic as a dielectric material inside the component, possibly with different density (thus adding a degree of freedom in the design); the other is based on the use of the plastic material as a mere support of the metallization, to reduce the losses.

The paper is organized as follows: Section 2 illustrates the major classes of AM techniques, according to the standard classification. Section 3 describes applications where the AM plastic is used a dielectric material inside the microwave components. Section 4 presents a variety of components (mainly microwave filters), where the AM plastic has the role to support the metallization, with no contact with the electromagnetic field.

\section{Additive Manufacturing Techniques}

In 2010, the American Society for Testing and Materials (ASTM) group "ASTM F42 - Additive Manufacturing" classified the additive manufacturing technologies into seven types:

1) Material Extrusion. This is one of the cheapest technologies. It is based on a filament of plastic material heated, extruded by a nozzle, and deposited layer-by-layer.

2) VAT Photo-polymerization. In that case, a liquid photosensitive polymer contained in a vat is hardened layer-by-layer by an UV laser.

3) Powder Bed Fusion. The 3D object is manufactured layer-by-layer by melting or sintering powder material. This technology allows the manufacturing of metal objects.

4) Material Jetting. This technology is similar to the inkjet printer, where liquid droplets are dispensed. In this case, however, a photosensitive polymer is used and hardened with UV light to manufacture 3D object layer-by-layer. 


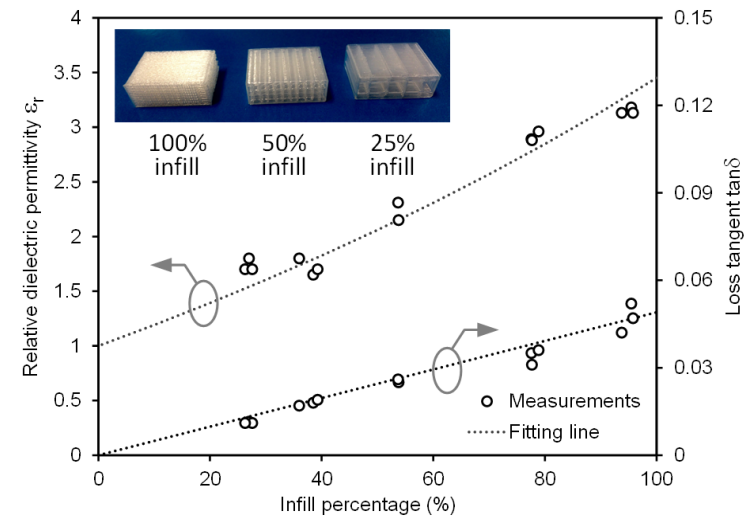

Fig. 1. Characterization of dielectric permittivity and loss tangent versus the infill percentage (from [17]).

5) Binder Jetting. Similar to material jetting but it uses two materials: powdered base material and a binder material. The binder material is dispensed onto the powdered material for adhesion of layers.

6) Sheet Lamination. Here, sheets or ribbons of metal or paper are bound together to form 3D objects.

7) Directed Energy Deposition. In this case, a nozzle holds a material in a wire form and an electron beam projector melts it. The process is similar to material extrusion, but the nozzle can move in multiple directions as in four- and five-axes machines.

\section{AM Plastics as Dielectric Materials}

\subsection{Tuning the Dielectric Permittivity}

The use of the material extrusion technique allows modifying the density of the printed dielectric material, thus adding a degree of freedom in the design of microwave components [5], [16], [17]. In particular, by selecting the infill percentage in the printing process, different values of dielectric permittivity as well as of loss tangent can be achieved.

In [17], a thermoplastic polyurethane Ninjaflex ${ }^{\circledR}$ filament, with diameter $1.75 \mathrm{~mm}$, was adopted for printing via fused deposition modeling (FDM). For measurement purposes, a set of samples were fabricated, with boxed shape and different infill percentage (specifically, with nominal infill of $100 \%, 50 \%$, and $25 \%$ ). The dielectric effective permittivity and loss tangent of the samples were measured by using a waveguide technique, and the actual infill of each sample was estimated from the volume and the weight of each specimen. Results are shown in Fig. 1.

\subsection{Slab Waveguide}

The possibility to realize different dielectric permittivity values by using one single filament was exploited in [17], where a 3D-printed substrate integrated slab waveguide (SISW) was proposed. The SISW [18] is similar to the

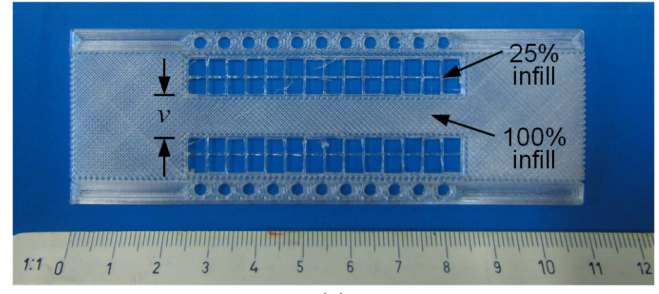

(a)

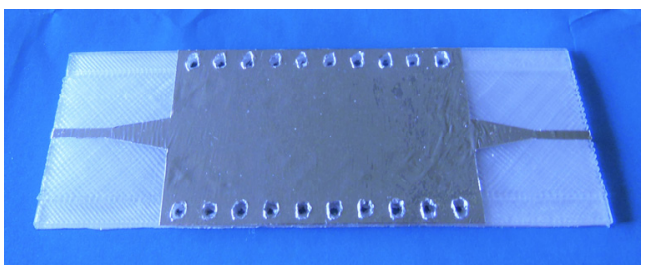

(b)

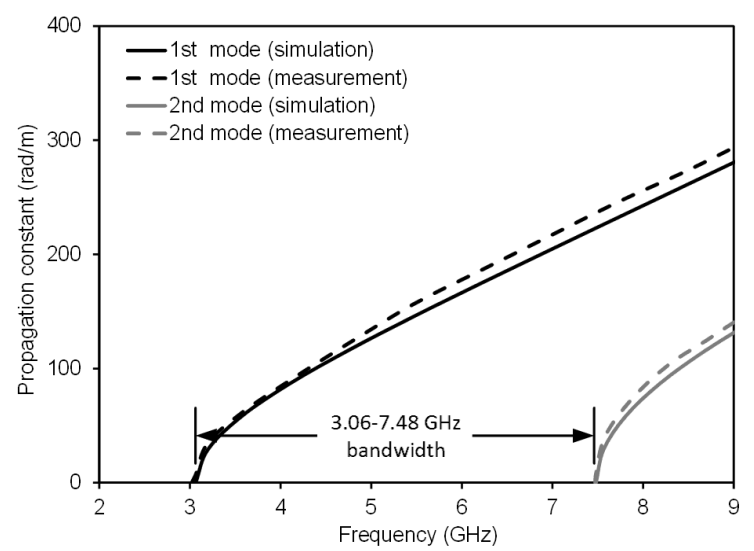

(c)

Fig. 2. 3D-printed substrate integrated slab waveguide: (a) Photograph of SISW interconnect (prior to pasting the aluminum foils and adding the metal vias). (b) Photograph of SISW interconnect after pasting the aluminum foil. (c) Simulated and measured propagation constant versus frequency (from [17]).

substrate integrated waveguide (SIW) [19], [20], but it permits to achieve broader single-mode bandwidth. It consists of a central portion with higher dielectric permittivity (where the electric field of the fundamental, quasi- $\mathrm{TE}_{10}$ mode is more intense) and two side portions with lower dielectric permittivity (where the second, quasi- $\mathrm{TE}_{20}$ mode is stronger). Using a lower permittivity in the side portion increases the cutoff frequency of the second mode, with almost no effect on the fundamental mode, thus expanding the single-mode band.

A SISW with $100 \%$ infill in the central portion and $25 \%$ infill in the side portions, covering the single-mode band from $3 \mathrm{GHz}$ to $7.5 \mathrm{GHz}$, was presented in [17] (Fig. 2a). The material used in this case is a filament of Ninjaflex (with dielectric permittivity $\varepsilon_{\mathrm{r}}=3.05$ and loss $\operatorname{tangent} \tan \delta=0.05$ for $100 \%$ infill). The top and bottom metal layers were implemented by aluminum foils (Fig. 2b) and the metal vias were realized by conductive paste.

This bandwidth is much larger than the one of the corresponding standard SIW, limited to the range $3 \mathrm{GHz}$ to $6 \mathrm{GHz}$. Simulations and measurements of the propagation 
constant versus frequency for the first and second modes demonstrated the operation principle (Fig. 2c).

\subsection{Microfluidic Sensor}

Another significant advantage of the AM is the possibility to manufacture arbitrarily shaped components, which can hardly be fabricated by conventional techniques. An example is shown in [2], where an SIW structure forming a bridge was realized by $3 \mathrm{D}$ printing with no need of any support material.

A microfluidic sensor, based on a resonant cavity with a micro-pipe printed directly inside the cavity (Fig. 3a), was proposed in [21]. The flexibility of the AM allows to print the pipe together with the cavity, in onepass fabrication process. The operation principle of the sensor is the following: when a liquid is injected inside the pipe, the effective permittivity of the material inside the cavity, as well as its effective loss tangent, are modified. Consequently, the resonance frequency and the quality factor of the cavity modes change. By measuring the variation of the resonance frequency and of the quality factor of the fundamental cavity mode, with and without liquid in the pipe, it is possible to retrieve the dielectric characteristics of the liquid.

A prototype of the microfluidic sensor based on the SIW resonant cavity was fabricated by 3D printing, using a filament of Ninjaflex (Fig. 3b), and the structure was metalized by using aluminum foils and conductive paste, as described in the previous subsection.

Full-wave simulations were performed to estimate the frequency shift $\Delta f$ with respect to the case of empty pipe, when different liquids with dielectric permittivity $\varepsilon_{\mathrm{r}}$ are injected in the pipe. The simulated frequency shift versus the value of dielectric permittivity is shown in Fig. 3c (black circles and dashed interpolating line). In the measurement phase, a liquid was injected into the pipe, the frequency shift was measured, and the simulation curve was used to retrieve the corresponding value of dielectric permittivity [21].

A more rigorous and accurate way to retrieve dielectric permittivity and loss tangent from the measurement of frequency shift and quality factor was presented in [22].

\section{AM Plastics as Metal Support}

A wide class of microwave components only consists of metal and does not require any dielectric materials. However, it is still possible to use plastic 3D printing to manufacture such components. In this case, the plastic is adopted to manufacture the mechanical structure, which is eventually metal-plated.

3D-printed objects can be metal-plated by simply painting them with conducting paint. However, the resulting surface conductivity may be too low for some microwave

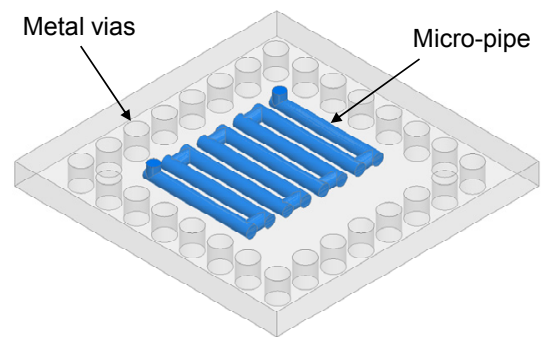

(a)

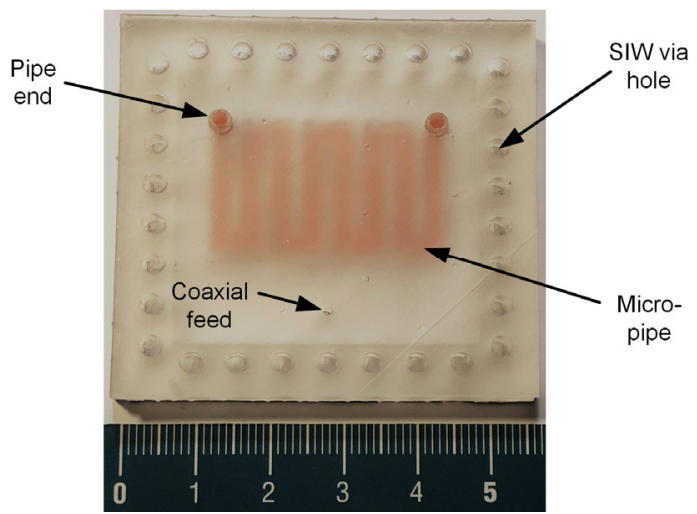

(b)

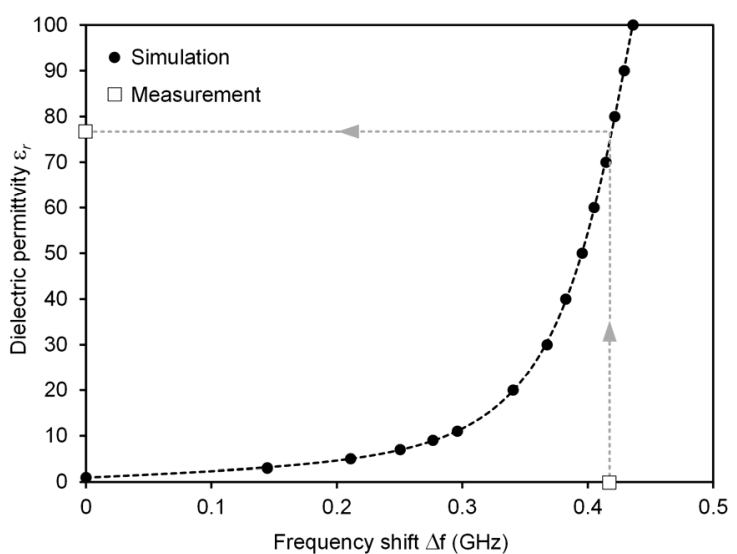

(c)

Fig. 3. 3D-printed microfluidic sensor based on an SIW cavity resonator: (a) Drawing of the structure. (b) Photograph of prototype (prior to pasting the aluminum foils and adding the metal vias). (c) Simulated and measured values of the dielectric permittivity of the liquid in the pipe versus the frequency shift (from [21]).

applications. In that case, however, the value of the surface conductivity can be dramatically increasing by adopting a subsequent electro-plating [23].

Another possibility is to use the dip-coating technique. This technique consists in dipping the manufactured plastic component into a liquid that it is able to metallize the plastic surface. The advantage of this technique is that it can be also used to metallize internal surfaces, provided that the liquid can access the internal parts of the component (for instance, through small holes). Also in this case, if the surface conductivity is not satisfactory, the structure can be post-processed by electro-plating.

All structures presented in this section were manufactured by the stereolithography (SLA) technology. 


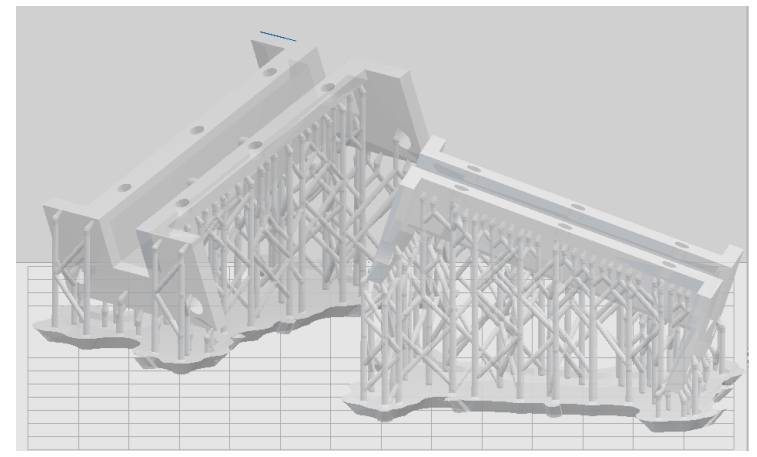

Fig. 4. Software driving the 3D printing: two half waveguides and the relevant supporting structures.

\subsection{Rectangular Cavity Filters}

The filters represent a class of components that require a very good surface conductivity. Rectangular waveguide filters are the most common non-planar filters and represent a good benchmark for testing AM technology combined with metal-plating.

Considering that in AM each layer is manufactured by adding material on the previous layer, there are some restrictions in allowed geometries. In order to mitigate the problem, the software driving 3D-printers allows the orientation of the component to be manufactured, as shown in Fig. 4 , in case of two half waveguides. The orientation is allowed thanks to the supporting structures. Supporting structures have also the additional scope of permitting the manufacturing of those portions of layers that cannot be supported by the previous layers, like suspended horizontal planes. Supporting structures are subsequently removed after manufacturing. In addition to such strategies, an AMoriented design is also advised.

Two examples are illustrated in Fig. 5a and Fig. 5b, where a single cavity and a 3-pole filter with rounded irises are shown [23]. Indeed, rounded surfaces are easier to be manufactured with 3D-printing. Figure $5 \mathrm{c}$ reports the comparison of measurements, HFSS simulations, and coupling matrix response of the 3-pole filter. The copper-plated 3Dprinted filter presents insertion losses comparable to that of a metallic waveguide [23].

\subsection{Mushroom-Shaped Post Filters}

Band-pass filters using capacitive posts as resonators (e.g., comb-line filters) have the advantage of being compact, and generally show a wide spurious-free stop band. Usually, they can be easily manufactured by using the traditional milling technique [25], [26]. By increasing the capacity between the post and the top wall of the waveguide, it is possible to minimize the filter dimension. This effect can be achieved by adopting mushroom-shaped posts [27]. However, this structure is more difficult to manufacture with traditional milling techniques. In particular, the post and the cavity cannot be milled together; they shall be manufactured separately and then assembled, thus generating

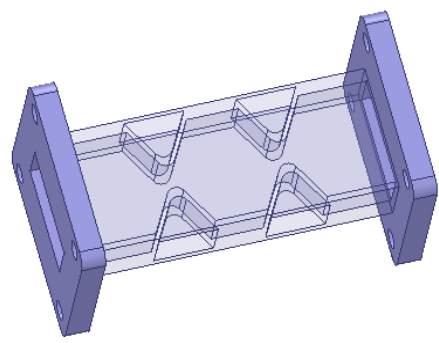

(a)

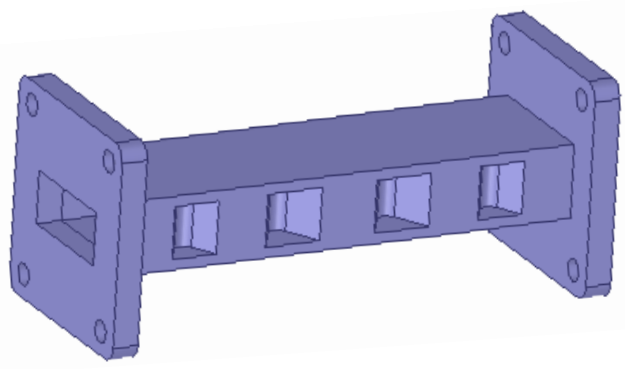

(b)

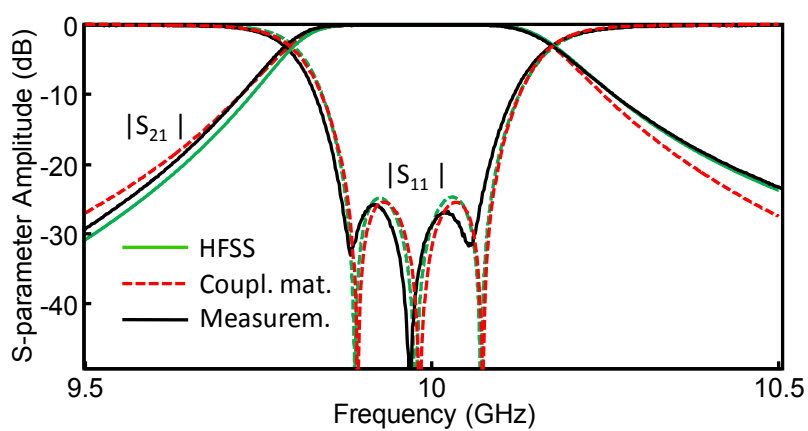

(c)

Fig. 5. AM-oriented design: rounded irises. (a) Geometry of the single cavity. (b) Geometry of the third-order bandpass filter. (c) Third-order filter response (from [23]).

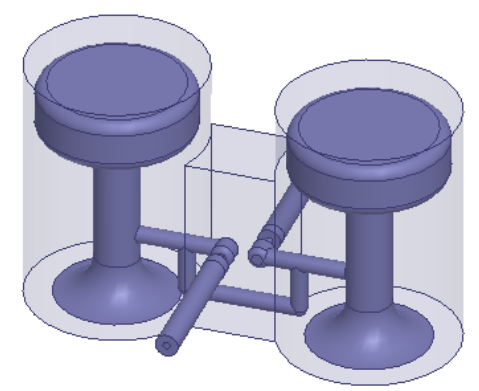

Fig. 6. Mushroom-shaped post doublet: building block used for the design of higher order filters [29].

problems related to possibly lossy contact between post and cavity.

This problem can be overcome by using the AM technology, that allows to implement posts with arbitrary shapes and realized them in one pass, together with the cavity.

Furthermore, by exploiting the high flexibility of the AM, component with more complex geometry can be designed, like the one shown in Fig. 6. In this structure, a conveniently shaped metal wire connects the two mush- 
room-shaped posts [28]. Thanks to the particular shape of the metal wire, a precise control of filter transmission zeros can be attained, as shown in [29].

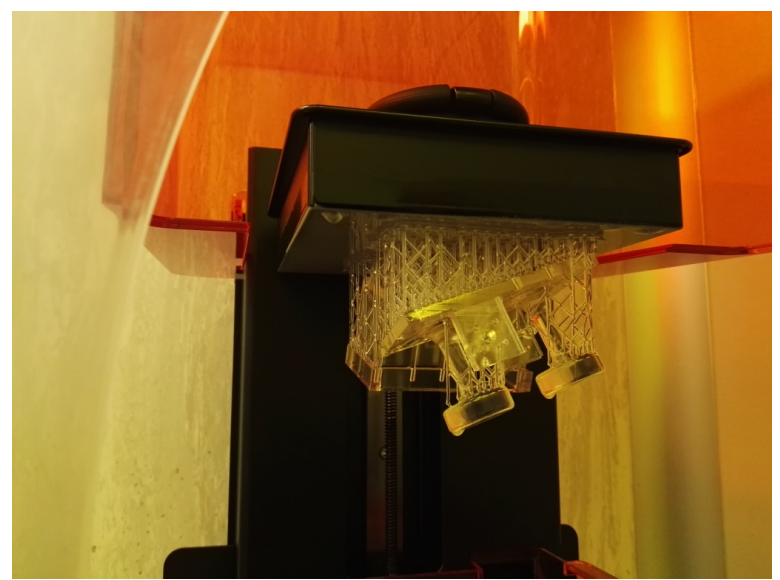

Fig. 7. Photograph of the manufactured four-pole filter inside the SLA 3D-printer building chamber [29].

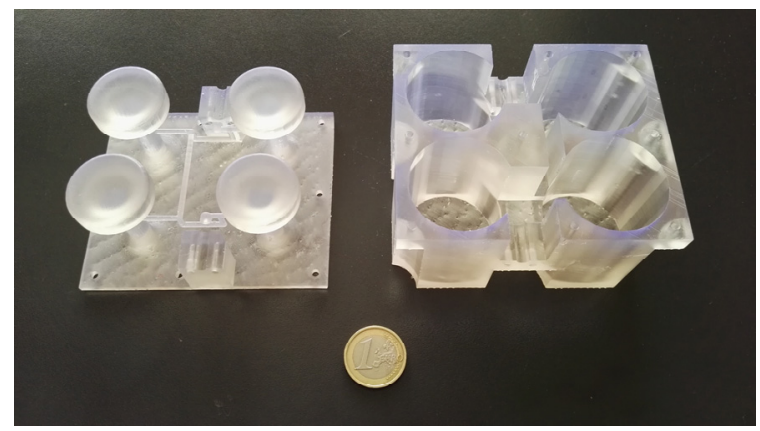

(a)

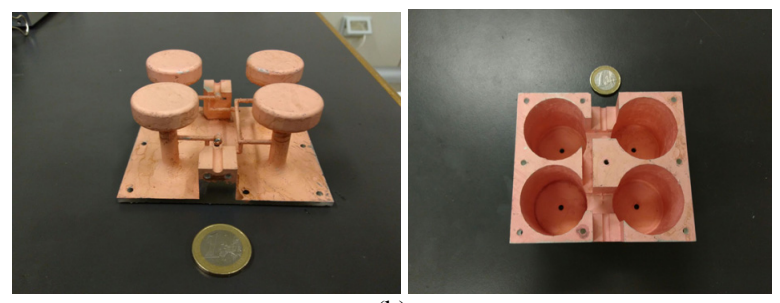

(b)

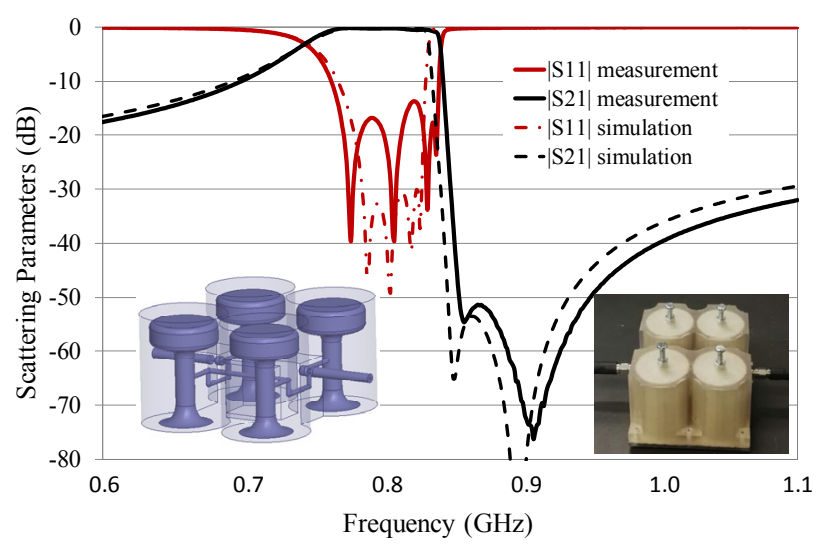

(c)

Fig. 8. Four-pole mushroom-shaped post filter and its cover: (a) Photograph before copper-plating. (b) Photograph after copper-plating. (c) Simulated and measured filter response [29].
The structure illustrated in Fig. 6 is a building block that can be used to obtain higher order filters [30], [31]. Higher order filters are obtained by cascading building blocks through non-resonating nodes [32]-[34]. Non-resonating nodes can be realized by quarter-wave waveguide sections [35], [36].

A filter with four poles and four transmission zeros, obtained by cascading two doublets, was designed and manufactured with the SLA 3D printer. Figure 7 shows the manufactured filter during the final part of the printing phase. Supporting structures and component orientation are well visible.

Figure 8 shows the filter after removing the supporting structures. The structure is divided into two pieces: the base with mushroom shaped posts and the cover. In particular, Figure 8a shows the filter before the metallization, whereas Figure $8 \mathrm{~b}$ shows the copper-plated filter. In Fig. $8 \mathrm{c}$ the comparison between measurements and simulations is shown. Despite in the graph only two transmission zeros are visible, the filter response presents four transmission zeros: this is because each transmission zero is a double transmission zero, which is a consequence of the adopted design. Thanks to a property of non-resonant nodes, all doublet transmission zeros remain in their original position after cascading the doublets. The double transmission zeros of the four-pole filter depend on the fact that the cascaded doublets, being identical, have transmission zeros located at the same frequency.

Mixed capacitive/inductive couplings to obtain transmission zeros have been exploited in different technologies, such as waveguide [37] or microstrip [38]. The basic idea is that inductive and capacitive couplings have a different sign. Furthermore, one increases with frequency whereas the other decreases. At a certain frequency, they cancel each other, thus generating a transmission zero. This idea has been also applied to post filter, as described in [39], [40], where the capacitive coupling is obtained by using additional elements such as strips [39] or lumped capacitors [40] soldered between two adjacent resonators. However, as shown in [12], by exploiting the AM flexibility it is possible to avoid additional elements. The mixed capacitive/inductive coupling has been obtained by modifying the geometry of the mushroom-shaped posts. As shown in Fig. 9a, cups of mushroom-shaped posts have been modified to obtain a capacitive coupling between adjacent resonators. The wire connecting the two adjacent posts is used to obtain inductive coupling [12]. The filter in Fig. 9a is then assembled with its cover, obtaining posts in an evanescent waveguide. The measured results are shown in Fig. $9 b$.

\subsection{Thin-septum Filter}

The last example of microwave filters is manufactured on a very thin septum [41], [42]. Two slant posts acting as resonators are attached to the septum. The slant angle is exploited to select the desired coupling. Coupling 
between the resonant posts are obtained thorough apertures in the septum (Fig. 10). Post and aperture positioning allows for the fine control of transmission-zero position [41], [42]. This solution is very useful when an additional filter with not very high performance is needed in an existing system. The insertion of such a small filter practically leaves the system size unchanged. Moreover, it is very easy to insert this filter between two waveguides connected by flanges. This mounting is clearly shown in Fig. 11, where the thin septum filter is inserted between the two waveguides of the network analyzer calibration kit. The thickness of the filter is negligible compared to the waveguides.

Figure 12a shows the photo of the manufactured and copper-plated two-pole filter. This filter is very flexible in terms of positioning of the transmission zeros [41], [42]. The example here reported shown such a flexibility. Figure $12 b$ illustrates the frequency response of a filter with two transmission zeros, one located above and the other below the filter passband, [41].

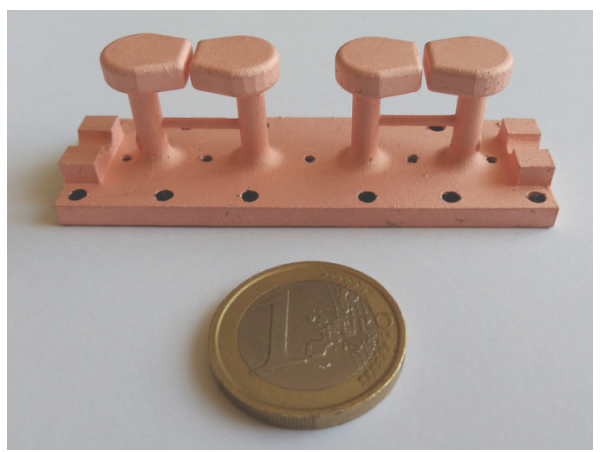

(a)

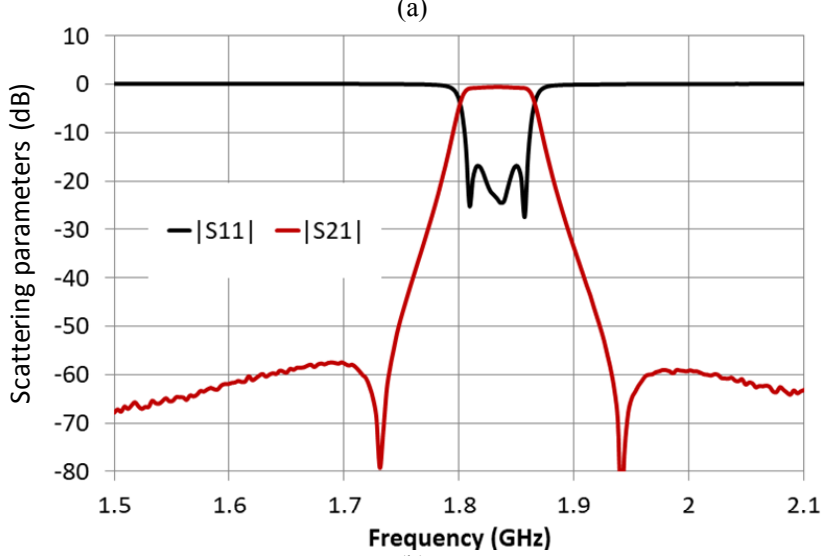

(b)

Fig. 9. Four-pole mixed capacitive/inductive coupling filter. (a) Photograph of the filter structure without cover. (b) Frequency response of the filter [12].

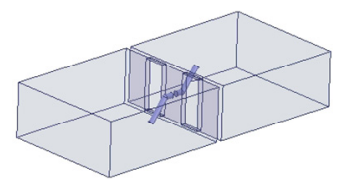

(a)

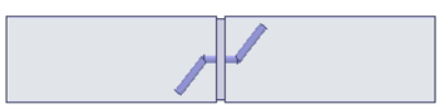

(b)
Fig. 10. Thin-septum filter mounted in a rectangular waveguide. (a) 3D view. (b) Side view.
Conversely, Figure 12c shows the frequency response of another similar filter, attained with a different arrangement of the thin septum, with two transmission zeros in the upper stopband [42]. In both cases the comparisons between measured and simulated results are reported.

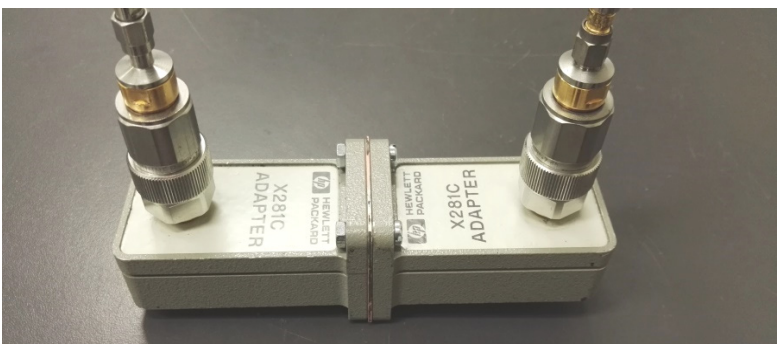

Fig. 11. Thin septum filter inserted between the waveguides of the network analyzer calibration kit.

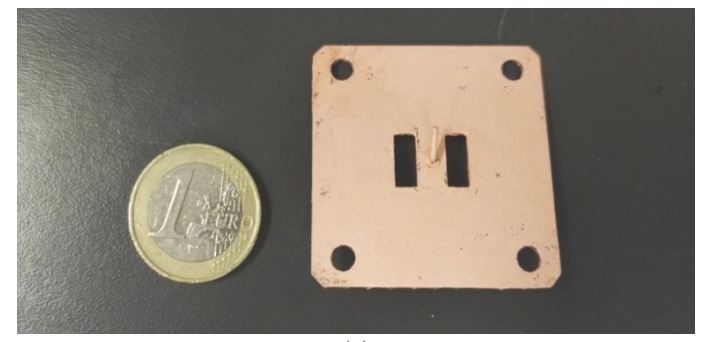

(a)

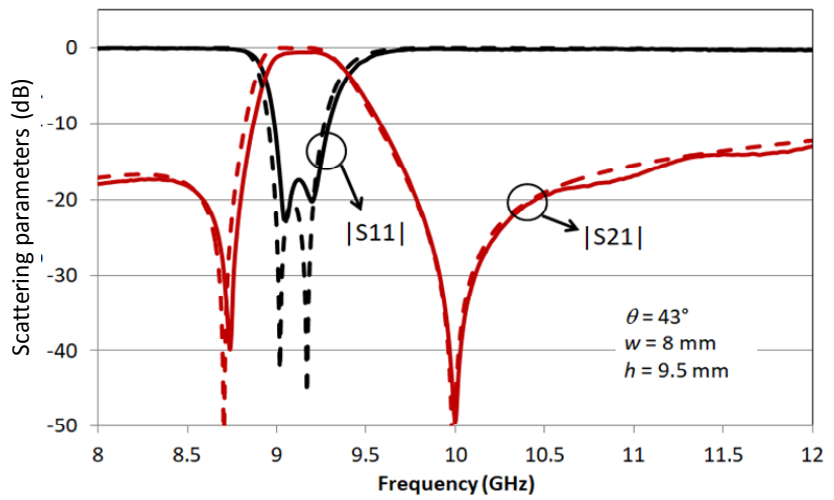

(b)

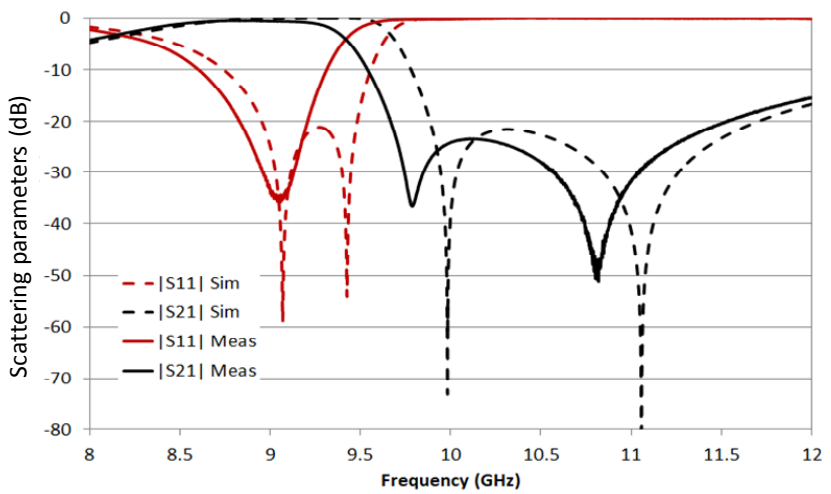

(c)

Fig. 12. Thin septum filter. (a) Photo of the structure. (b) Simulated and measured response with one transmission zero in the upper and one in the lower stop-band [41]. (c) Simulated and measured response with two transmission zeros in the upper stop-band [42]. 


\section{Acknowledgments}

The authors wish to acknowledge Prof. Luca Perregrini, Prof. Ferdinando Auricchio, and several current and former researchers and students at the University of Pavia, Italy; Prof. Roberto Sorrentino, Dr. Giuseppe Venanzoni and Dr. Marco Dionigi at the University of Perugia, Italy; Prof. Manos Tentzeris and his group at the Georgia Institute of Technology, Atlanta, USA.

\section{References}

[1] D'AURIA, M., OTTER, W. J., HAZELL, J., et al. 3-D printed metal-pipe rectangular waveguides. IEEE Transactions on Components, Packaging and Manufacturing Technology, 2015, vol. 5, no. 9, p. 1339-1349. DOI: 10.1109/TCPMT.2015.2462130

[2] MOSCATO, S., BAHR, R., LE, T., et al. Additive manufacturing of 3D substrate integrated waveguide components. Electronics Letters, 2015, vol. 51, no. 18, p. 1426-1428. DOI: $10.1049 / \mathrm{el} .2015 .2298$

[3] MIN LIANG, SHEMELYA, C., MACDONALD, E., et al. 3-D printed microwave patch antenna via fused deposition method and ultrasonic wire mesh embedding technique. IEEE Antennas and Wireless Propagation Letters, 2015, vol. 14, p. 1346-1349. DOI: 10.1109/LAWP.2015.2405054

[4] GUO, C., SHANG, X., LI, J., et al. A lightweight 3-D printed Xband bandpass filter based on spherical dual-mode resonators. IEEE Microwave and Wireless Components Letters, 2016, vol. 26, no. 8, p. 568-570. DOI: 10.1109/LMWC.2016.2587838

[5] MOSCATO, S., BAHR, R., LE, T., et al. Infill dependent 3Dprinted material based on NinjaFlex filament for antenna applications. IEEE Antennas and Wireless Propagation Letters, 2016, vol. 15, p. 1506-1509. DOI: 10.1109/LAWP.2016.2516101

[6] CHIO, T., HUANG, G., ZHOU, S. Application of direct metal laser sintering to waveguide-based passive microwave components, antennas, and antenna arrays. Proceedings of the IEEE, 2017, vol. 105, no. 4, p. 632-644 DOI: 10.1109/JPROC.2016.2617870

[7] PEVERINI, O. A., LUMIA, M., CALIGNANO, F., et al. Selective laser melting manufacturing of microwave waveguide devices. Proceedings of the IEEE, 2017, vol. 105, no. 4, p. 620-631. DOI: 10.1109/JPROC.2016.2620148

[8] MAAS, J., LIU, B., HAJELA, S., et al. Laser-based layer-by-layer polymer stereolithography for high-frequency applications. Proceedings of the IEEE, 2017, vol. 105, no. 4, p. 645-654. DOI: 10.1109/JPROC.2016.2629179

[9] ROJAS-NASTRUCCI, E. A., NUSSBAUM, J. T., CRANE, N. B., et al. Ka-band characterization of binder jetting for 3-D printing of metallic rectangular waveguide circuits and antennas. IEEE Transactions on Microwave Theory and Techniques, 2017, vol. 65, no. 9, p. 3099-3108. DOI: 10.1109/TMTT.2017.2730839

[10] VERPlOEGH, S., COFFEY, M., GROSSMAN, E., et al. Properties of $50-110-\mathrm{GHz}$ waveguide components fabricated by metal additive manufacturing. IEEE Transactions on Microwave Theory and Techniques, 2017, vol. 65, no. 12, p. 5144-5153. DOI: 10.1109/TMTT.2017.2771446

[11] DAHLE, R., LAFORGE, P., KUHLING, J. 3-D printed customizable inserts for waveguide filter design at X-band. IEEE Microwave and Wireless Components Letters, 2017, vol. 27, no. 12, p. 1080-1082. DOI: 10.1109/LMWC.2017.2754345
[12] VENANZONI, G., DIONIGI, M., TOMASSONI, C., et al. 3-Dprinted quasi-elliptical evanescent mode filter using mixed electromagnetic coupling. IEEE Microwave and Wireless Components Letters, 2018, vol. 28, no. 6, p. 497-499. DOI: 10.1109/LMWC.2018.2829627

[13] ADDAMO, G., PEVERINI, O. A., MANFREDI, D., et al. Additive manufacturing of Ka-band dual-polarization waveguide components. IEEE Transactions on Microwave Theory and Techniques, 2018, vol. 66, no. 8, p. 3589-3596. DOI: 10.1109/TMTT.2018.2854187

[14] SHEN, J., RICKETTS, D. S. Additive manufacturing of complex millimeter-wave waveguides structures using digital light processing. IEEE Transactions on Microwave Theory and Techniques, 2019, vol. 67, no. 3, p. 883-895. DOI: 10.1109/TMTT.2018.2889452

[15] DISTLER, F., SIPPEL, M., SCHÜR, J., et al. Additively manufactured dielectric waveguides for advanced concepts for millimeter-wave interconnects. IEEE Transactions on Microwave Theory and Techniques, 2019, vol. 67, no. 11, p. 4298-4307. DOI: 10.1109/TMTT.2019.2939831

[16] TOMASSONI, C., BAHR, R., BOZZI, M., et al. 3D printed substrate integrated waveguide filters with locally controlled dielectric permittivity. In 46th European Microwave Conference (EuMC2016). London (UK), Oct. 4-6, 2016, p. 253-256. DOI: 10.1109/EuMC.2016.7824326

[17] MASSONI, E., SILVESTRI, L., ALAIMO, G., et al. 3D-printed substrate integrated slab waveguide for single-mode bandwidth enhancement. IEEE Microwave and Wireless Components Letters, 2017, vol. 27, no. 6, p. 536-538. DOI: 10.1109/LMWC.2017.2701323

[18] BOZZI, M., DESLANDES, D., ARCIONI, P., et al. Efficient analysis and experimental verification of substrate integrated slab waveguides for wideband microwave applications. International Journal of RF and Microwave Computer-Aided Engineering, 2005, vol. 15 , no. 3, p. 296-306. DOI: $10.1002 /$ mmce. 20085

[19] BOZZI, M., GEORGIADIS, A., WU, K. Review of substrate integrated waveguide (SIW) circuits and antennas. IET Microwaves, Antennas and Propagation, 2011, vol. 5, no. 8, p. 909-920. DOI: 10.1049/iet-map.2010.0463

[20] GARG, R., BAHL, I., BOZZI, M. Microstrip Lines and Slotlines. $3^{\text {rd }}$ ed. Artech House, 2013. ISBN: 978-1608075355

[21] MOSCATO, S., PASIAN, M., BOZZI, M., et al. Exploiting 3D printed substrate for microfluidic SIW sensor. In 45th European Microwave Conference (EuMC2015). Paris (France), Sept. 7-10, 2015, p. 28-31. DOI: 10.1109/EuMC.2015.7345691

[22] ROCCO, G. M., BOZZI, M., SCHREURS, D., et al. 3D-printed microfluidic sensor in SIW technology for liquids characterization. IEEE Transactions on Microwave Theory and Techniques, 2020, vol. 68, p. 1-10. Early access 17 Dec 2019. DOI: 10.1109/TMTT.2019.2953580

[23] DIONIGI, M., TOMASSONI, C., VENANZONI, G., et al. Simple high-performance metal-plating procedure for stereolithographically 3D-printed waveguide components. IEEE Microwave and Wireless Components Letters, 2017, vol. 27, no. 11, p. 953-955. DOI: 10.1109/LMWC.2017.2750090

[24] GETERUD, E. G., BERGMARK, P., YANG, J. Lightweight waveguide and antenna components using plating on plastics. In 7th European Conference on Antennas and Propagation (EuCAP 2013). Gothenburg (Sweden), 2013, p. 1812-1815. ISBN: 978-88-907018-3-2

[25] TOMASSONI, C., SORRENTINO, R. A new class of pseudoelliptic waveguide filters using resonant posts. In IEEE/MTT-S International Microwave Symposium Digest (IMS 2012). Montreal (QC, Canada), 2012, p. 1-3. DOI: 10.1109/MWSYM.2012.6259395 
[26] TOMASSONI, C., SORRENTINO, R. A new class of pseudoelliptic waveguide filters using dual-post resonators. IEEE Transactions on Microwave Theory and Techniques, 2013, vol. 61, no. 6, p. 2332-2339. DOI: 10.1109/TMTT.2013.2258171

[27] GENTILI, F., PELLICCIA, L., SORRENTINO, R., et al. High Qfactor compact filters with wide-band spurious rejection. In 42 nd European Microwave Conference (EuMC 2012). Amsterdam (The Netherlands), 2012, p. 160-163. DOI: 10.23919/EuMC.2012.6459271

[28] TOMASSONI, C., VENANZONI, G., DIONIGI, M., et al. Compact doublet structure for quasi-elliptical filters using stereolitographic 3D printing. In 47th European Microwave Conference (EuMC 2017). Nuremberg (Germany), 2017, p. 993-996. DOI: 10.23919/EuMC.2017.8231013

[29] TOMASSONI, C., VENANZONI, G., DIONIGI, M., et al. Compact quasi-elliptic filters with mushroom-shaped resonators manufactured with 3-D printer. IEEE Transactions on Microwave Theory and Techniques, 2018, vol. 66, no. 8, p. 3579-3588. DOI: 10.1109/TMTT.2018.2849067

[30] Pelliccia, L., CACCIAMANi, F., TOMASSONI, C., et al. Ultra-compact high-performance filters based on TM dual-mode dielectric-loaded cavities. International Journal of Microwave and Wireless Technologies, 2014, vol. 6, no. 2, p. 151-159. DOI: $10.1017 / \mathrm{S} 1759078713001001$

[31] PELlicCia, L., CACCIAMANI, F., TOMASSONI, C., et al. Ultra-compact filters using TM dual-mode dielectric-loaded cavities with asymmetric transmission zeros. In IEEE/MTT-S International Microwave Symposium Digest (IMS 2012). Montreal (QC, Canada), 2012, p. 1-3. DOI: 10.1109/MWSYM.2012.6258411

[32] BASTIOLI, S., TOMASSONI, C., SORRENTINO, R. A new class of waveguide dual-mode filters using TM and nonresonating modes. IEEE Transactions on Microwave Theory and Techniques, 2010, vol. 58, no. 12, p. 3909-3917. DOI: 10.1109/TMTT.2010.2086068

[33] BASTiOLI, S., MARCACCIOLI, L., TOMASSONI, C., et al. Ultracompact highly-selective dual-mode pseudoelliptic filters. IET Electronics Letters, 2010, vol. 46, no. 2, p. 147-149. DOI: 10.1049/el.2010.2971

[34] TOMASSONI, C., BASTIOLI, S., SORRENTINO, R. Generalized TM dualmode cavity filters. IEEE Transactions on Microwave Theory and Techniques, 2011, vol. 59, no. 12, p. 3338-3346. DOI: 10.1109/TMTT.2011.2172622

[35] TOMASSONI, C., BASTIOLI, S., SNYDER, R. V. Propagating waveguide filters using dielectric resonators. IEEE Transactions on Microwave Theory and Techniques, 2015, vol. 63, no. 12, p. 4366-4375. DOI: 10.1109/TMTT.2015.2495284

[36] TOMASSONI, C., BASTIOLI, S., SNYDER, R. V. Compact mixed-mode filter based on $\mathrm{TE}_{101}$ cavity mode and $\mathrm{TE}_{01 \delta}$ dielectric mode. IEEE Transactions on Microwave Theory and Techniques, 2016, vol. 64 , no. 12, p. 4434-4443. DOI: 10.1109/TMTT.2016.2623714

[37] KOZAKOWSKI, P., LAMECKI, A., MONGIARDO, M., et al. Computer-aided design of in-line resonator filters with multiple elliptical apertures. In IEEE MTT-S International Microwave Symposium Digest (IMS 2004). Fort Worth (TX, USA), 2004, p. 611-614. DOI: 10.1109/MWSYM.2004.1336058

[38] XIAO, J. K., ZHU, M., TIAN, L., et al. High selective microstrip bandpass filter and diplexer with mixed electromagnetic coupling. IEEE Microwave and Wireless Components Letters, 2015, vol. 25, no. 12, p. 781-783. DOI: 10.1109/LMWC.2015.2495194

[39] WANG, H., CHU, Q. X. An inline coaxial quasi-elliptic filter with controllable mixed electric and magnetic coupling. IEEE Transactions on Microwave Theory and Techniques, 2009, vol. 57, no. 3, p. 667-673. DOI: 10.1109/TMTT.2009.2013290

[40] BASTIOLI, S., SNYDER, R. V., JOJIC, P. High power in-line pseudoelliptic evanescent mode filter using series lumped capacitors. In Proceedings of the $41^{\text {st }}$ European Microwave Conference (EuMC 2011). Manchester (UK), 2011, p. 87-89. DOI: 10.23919/EuMC.2011.6101723

[41] TOMASSONI, C., VENANZONI, G., DIONIGI, M., et al. A very compact 3D-printed doublet structure based on a double iris and a pair of slanting rods. In IEEE MTT-S International Microwave Symposium (IMS 2018). Philadelphia (PA, USA), June 10-15, 2018, p. 1103-1105. DOI: 10.1109/MWSYM.2018.8439368

[42] TOMASSONI, C., VENANZONI, G., DIONIGI, M., et al. Additive manufacturing of a very compact doublet structure with asymmetric filtering function. In International Microwave Workshop Series on Advanced Materials and Processes for $\mathrm{RF}$ and $\mathrm{THz}$ Applications (IMWS-AMP 2018). Ann Arbor (MI, USA), 2018, p. 1-3. DOI: 10.1109/IMWS-AMP.2018.8457127

\section{About the Authors ...}

Cristiano TOMASSONI was born in Spoleto, Italy. He received the Ph.D. degree in Electronics Engineering from the University of Perugia, Perugia, Italy, 1999. In 1999, he was a Visiting Scientist with the Lehrstuhl für Hochfrequenztechnik, Technical University of Munich, Munich, Germany, where he was involved with the modeling of waveguide structures and devices by using the generalized scattering matrix (GSM) technique. In 2001, he was a Guest Professor with the Fakultät für Elektrotechnik und Informationstechnik, Otto-von-Guericke University, Magdeburg, Germany. During that time, he was involved with the modeling of horn antennas having nonseparable cross sections by using hybrid methods combining three different techniques: the finite-element method (FEM), modematching technique (MMT), and generalized multipole technique (GMT). During his career, he was also involved in the modeling of low-temperature co-fired ceramics (LTCC) by using the method of moments (MoM). Furthermore, he studied new analytical methods to implement boundary conditions in the transmission-line matrix (TLM) method and he modeled aperture antennas covered by dielectric radome by using spherical waves. Since 2007, he has been an Assistant Professor with the University of Perugia, where he currently teaches the 'Aerospace Microwave and Radiofrequency Systems' course. His main area of research concerns the modeling and design of waveguide devices and antennas. His research interests also include the development of reduced-size cavity filters, reconfigurable filters, and printed reconfigurable antenna arrays. Cristiano Tomassoni is an Associate Editor of the IEEE Transactions on Microwave Theory and Techniques and a member of the MTT-8 Filters and Passive Components Technical Committee. He received the Best Paper Award (Second Place) at NEMO 2018 and the Best Paper Award (first place) at the 15th Mediterranean Microwave Symposium (MMS2015). He was the recipient of the 2012 Microwave Prize presented by the IEEE Microwave Theory and Technique Society (IEEE MTT-S), recognized to the authors of the paper judged to be the most significant contribution of the year in the field of interest of the MTT Society. 
Maurizio BOZZI received the Ph.D. degree in Electronics and Computer Science from the University of Pavia, Pavia, Italy, in 2000. He held research positions with various universities worldwide, including the Technische Universität Darmstadt, Germany; the Universitat de Valencia, Spain; and the École Polytechnique de Montréal, Canada. In 2002, he joined the Department of Electronics, University of Pavia, where he is currently a full Professor of electromagnetic fields. He was also a Guest Professor at Tianjin University, China (2015-2017) and a Visiting Professor at Gdansk University of Technology, Poland (2017-2018). He has authored or co-authored more than 130 journal papers and 300 conference papers. He co-edited the book Periodic Structures (Research Signpost, 2006) and co-authored the book Microstrip Lines and Slotlines (Artech House, 2013). His main research interests concern the computational electromagnetics, the substrate integrated waveguide technology, and the use of novel materials and fabrication technologies for microwave circuits. Prof. Bozzi is an Elected Member of the Administrative Committee of the IEEE Microwave Theory and Techniques Society (MTT-S) for terms 2017-2019 and 2020-2022, and he was the Chair of the Meeting and Symposia Committee of MTT-S AdCom for years 2018-2019. He was the Secretary of IEEE MTT-S for year 2016 and a member of the General Assembly (GA) of the European Microwave Association (EuMA) from 2014 to 2016. He is a track editor of the IEEE Transactions on Microwave Theory and
Techniques. He was an associate editor of the IEEE Microwave and Wireless Components Letters, IET Electronics Letters, and IET Microwaves, Antennas and Propagation. He was the Guest Editor of special issues in the IEEE Transactions on Microwave Theory and Techniques, the IEEE Microwave Magazine, and the IET Microwaves, Antennas and Propagation. He was the General Chair of the IEEE MTT-S International Microwave Workshop Series-Advanced Materials and Processes (IMWS-AMP 2017), in Pavia, Italy, 2017, of the inaugural edition of the IEEE International Conference on Numerical Electromagnetic Modeling and Optimization (NEMO2014), in Pavia, Italy, 2014, and of the IEEE MTT-S International Microwave Workshop Series on Millimeter Wave Integration Technologies, in Sitges, Spain, 2011. He received several awards, including the 2015 Premium Award for the Best Paper in IET Microwaves, Antennas \& Propagation, the 2014 Premium Award for the Best Paper in Electronics Letters, the Best Student Paper Award at the 2016 IEEE Topical Conference on Wireless Sensors and Sensor Networks (WiSNet2016), the Best Paper Award at the 15th Mediterranean Microwave Symposium (MMS2015), the Best Student Award at the 4th European Conference on Antennas and Propagation (EuCAP 2010), the Best Young Scientist Paper Award of the XXVII General Assembly of URSI in 2002, and the MECSA Prize of the Italian Conference on Electromagnetics (XIII RiNEm), in 2000. He is a Fellow of the IEEE. 